\title{
Colored Polymeric Microcomposites with Minimal Environmental Impact
}

\author{
MIRCEA RUSE ${ }^{1 *}$, SANDU PERETZ², ANCA ANGELA ATHANASIU ${ }^{1}$, LOTI CORNELIA OPROIU ${ }^{1}$, CATALIN FILIPESCU ${ }^{1}$, \\ RALUCA SENIN ${ }^{1}$ \\ ${ }^{1}$ National Research and Development Institute for Chemistry and Petrochemistry - ICECHIM, 202 Spl. Independentei, 060021, \\ Bucharest, Romania \\ ${ }^{2}$ Institute of Physical Chemistry I. Murgulescu - ICF (Academy), Bucharest, 202 Spl. Independentei, 060021, Bucharest, Romania
}

\begin{abstract}
The paper presents the research carried out by our team on achieving amphiphilic polymeric microcomposites, colored in ruby and violet shades for natural fibers dyeing (cotton, wool). The colored polymeric microcomposites were characterized in term of theirmorpholo- gical (byoptical microscopy and SEM analysis) and physicochemical performancies (byFT-IR and UV-Vis spectroscopy, colorimetric analysis). The colored microcapsules were tested by studying the controlled release of the encapsulated dyes in water, to $\mathrm{pH}$ variation. This study was necessary to the coloristic characterization of colored polymeric microcomposites to determine the optimal microcapsules dye concentration and dyeing concentration of natural fibers.
\end{abstract}

Keywords: amphiphilic, polymeric, microcapsules, colorimetric analysis

Microencapsulation is a process in which tiny particles or droplets are surrounded by a shell (membrane) to obtain small capsules with useful properties. Most of the microcapsules have a diameter from a few ì to several $\mathrm{mm}$. The definition was expanded and includes most medicines. There have been encapsulated a series of food ingredients and fragrances, in particular [1-3]. Further the technique of microencapsulation is expected to be applied to the organic and inorganic dyes and pigments class. The purpose of microencapsulation is the isolation of the active substance from the environment, of reactive and metal complex dye in our case, to defend them of the harmful effect of atmospheric oxygen and UV radiations and controlling the speed with which the dye leaves the microcapsule, such as: controlled release of the studied dyes from the microcapsule in water $[4,5]$. The paper presents the research carried out by bur team on achieving amphiphilic polymeric microcomp ssites, colored in ruby and violet shades for natural fibers iyeing (cotton, wool). It was developed the laboratory microencapsulation technology for reactive and met l-complex dyes in a biodegradable natural polymer ma rix (calcium alginate)

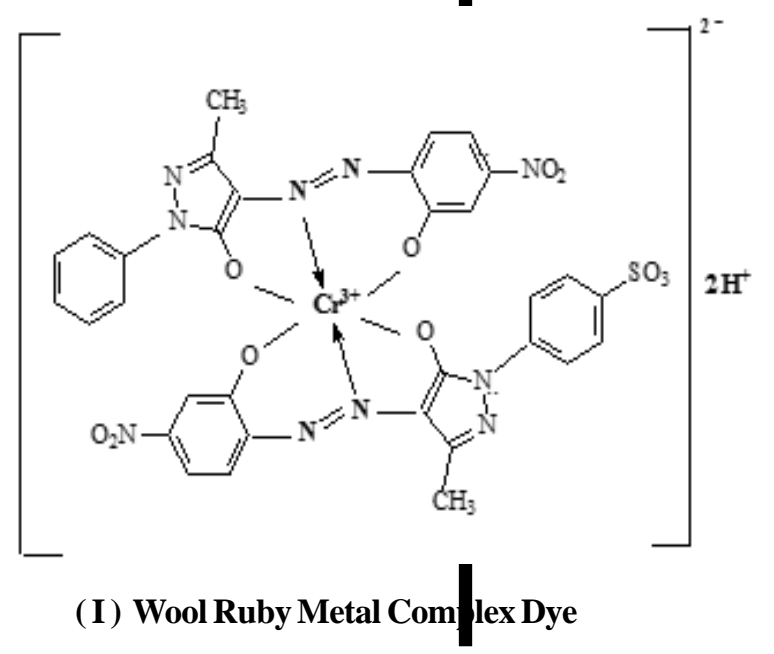

*email: mircearuse1@yahoo.com; Phone: +40 0726787868
[6-8]. As coloring materials were used reactive and metalcomplex dyes, synthesized by our team, previously analysed in terms of physicochemical (purity, concentration, FT-IR and UV-Vis spectral parameters) and coloristical performances (hue, intensity, dyeing concentration, resistance to light, water, wet and dry friction, acid and alkaline perspiration, solubility and degree of fleet exhaustion). Chemical formulas of the used dyes to achieve microencapsulation are (I), (II) and (III). Their performances are comparable to known foreign brands (BASF, ICl, Ciba). The colored polymeric microcomposites were characterized in terms of morphology (optical microscopy, SEM analysis) and physicochemical performances (FT-IR and UV-Vis spectroscopy, colorimetric analysis). The colored microcapsules were tested by studying the controlled release of the encapsulated dyes in water, to $\mathrm{pH}$ variation. This study is still necessary to the coloristic characterization of colored polymeric microcomposites, to determine the optimal microcapsules dye concentration and dyeing concentration of natural

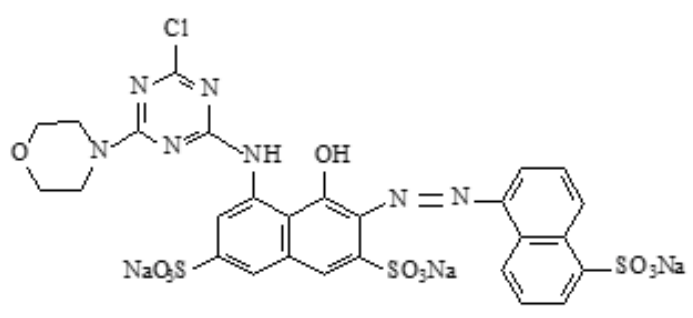

(II) Cotton Violet Reactive Dye<smiles></smiles>

(III) Cotton Ruby Reactive Dye 
fibers. The technologies used in obtaining and applying of colored microcomposites are green and are made with minimal specific consumption and according to currently existing environmental information, both raw materials (reactive and metal-complex dyes, anionic polymer, precipitating agent) and end products show reduced ecotoxicological risk.

\section{Experimental part}

Materials and equipment

Microencapsulation agent: sodium alginate (NaAlg); Precipitation agent: calcium chloride ( $\mathrm{CaCl}_{2}$ ); Colouring material: Ruby reactive dye, Violet reactive dye and Ruby metal-complex dye.

IR spectra were measured with a FT-IR - Jasco 6300 spectrophotometer, using KBr pellets UV-Vis spectra were performed in distilled water with a UV /Vis /NIR spectrophotometer, in 190-2500 nm range. Were used cells with $1 \mathrm{~cm}$ pathlenght, working in the range dye concentrations of $0.3-2.3 \cdot 10^{-2} \mathrm{~g} / \mathrm{L}$ in distilled water. UVVis JASCO V 570 spectrophotometer, in 190-2500 nm range. Optical Microscope - MAGNUM: trinocular head, with fluorescence system and magnification $x 20, x 40$, x100; fine focusing knob, min division: $0.002 \mathrm{~mm}$. SEM Scanning Electron Microscope with point resolution: 1.2 $\mathrm{nm}$ with focused ion beam (FIB).

\section{Synthesis}

Microcomposites synthesis was made into a capsule with large area with $d=26 \mathrm{~cm}$, which contained a colored solution of $6.2 \% \mathrm{CaCl}_{2}$ conc., equipped with an anchor stirrer and three dropping funnels in which was placed a solution of $1.7 \%$ NaAlg conc. NaAlg solution was dropped at ambient temperature within approx. $9 \mathrm{~h}$. The optimum amount of dye taken into work, was considered in relation to the used amount of NaAlg, reaching a value of approx. $0.43 \%$, corresponding to an optimal absorption of the dye inside the microcapsule and a weak colored solution load with minimal residual dye. After microencapsulation concluding, which lasted $48 \mathrm{~h}$, colored microcomposites suspension was filtered at vacuum and the resulted cake was washed with distilled water in three innings for removing of the unencapsulated dye and calcium chloride, whose presence disturbs the fibers dyeing. Finally, the wet colored microcomposites were dried to free air at $20-25^{\circ} \mathrm{C}$.

After drying, on handling of colored microcomposites does not remain dye on the fingers, which proves that the dye is embedded inside the microcapsules. Colored calcium alginate microcapsules have been isolated from the reaction mass, washed with distilled water and then were subjected to lyophilization (freeze-drying) process (drying at low temperature). Colored dried microcapsules can be stored in this way for a long time.

Colored waste water resulted from chemical synthesis, obtained through microencapsulation of the selected reactive dyes in shades of ruby and purple, were subjected to the laboratory procedures of fading/ treatment of wastewater containing anionic dyes, through anion exchange resins of A 500 PUROLITE type. These waters were passed through columns containing ion exchange resin beds with a view to eliminate mainly of coloring matters contained.

\section{Physico-chemical analysis}

The ruby azo chromium (1: 2) asymmetric complex dye, in solid form, used to prepare ruby colored microcomposites was synthesized by our team and belong to LANACRON (Ciba) dyes type for protein substrates dyeing (wool, silk, nylon, leather). By colorimetric analysis was determined its relative concentration of $70 \%$ having $\lambda_{\max }=515 \mathrm{~nm}$. Monoclortriazine reactive azo dyes, in liquid form, used to obtain colored microcomposites in ruby and violet shades were synthesized by our team and belong to Cibacron (Ciba Geigy) dyes type for cellulosic fibers (cotton) dyeing. By colorimetric analysis was determined their relative concentration to: Ruby reactive dye, $52 \mathrm{~g} / \mathrm{L}$ with $\lambda^{1}$ max $=545 \mathrm{~nm} ; \lambda^{2}=528 \mathrm{~nm}$; Violet reactive dye, 49 $\mathrm{g} / \mathrm{L}$ with $\lambda_{\text {max }}=543 \mathrm{~nm}$. Sodium alginate (NaAlg) was purchased from Aldrich company, with $99 \%$ conc., $2 \%$ solution at $25^{\circ} \mathrm{C}$ and viscosity is $\eta=250 \mathrm{cp}$. Colored polymeric microcapsules were morphologically (byoptical microscopy, SEM analysis) and physicochemical (by FT-IR and UV-Vis spectroscopy, colorimetric analysis) characterized. Also tests have been carried out to determine the controlled-release rate of the dye from the microcapsules in water by measuring the dye concentration variation of the solution, in time.

\section{Results and discussions}

Morphological characterization

Optical microscopy (microcapsules size determination)

CaAlg microcapsules were white. Optical microscopy determinations were made on lyophilized samples. We found that white microcapsules are in the quasi-spherical form with a size of $500 \mu \mathrm{m}$. For samples containing dye is found that colored microcapsules are larger, around 800$1200 \mu$.

\section{SEM (scanning electron microscopy)}

White microcapsules have a rough structure with pores in the scales form. This rough surface and their pores indicate that they are suitable for absorption of organic substances, such as dyes (fig. 1). Colored polymeric microcomposites containing reactive or metal-complex dyes are found to have a completely different look compared to the initial white polymeric microcomposites. Their surface is more compact and shows micro-cracks ( fig. 2 and fig. 3).

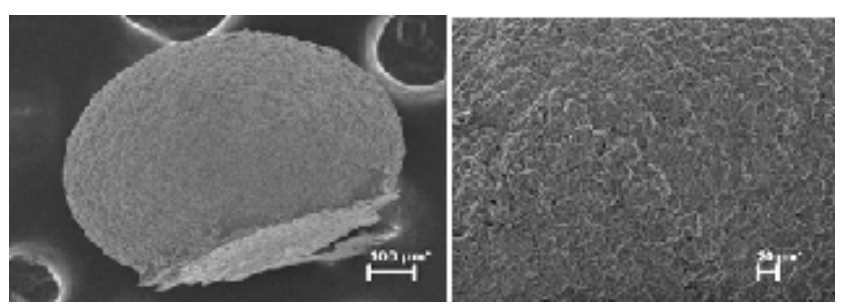

Fig. 1. a) White microcapsule b) The surface of white microcapsule

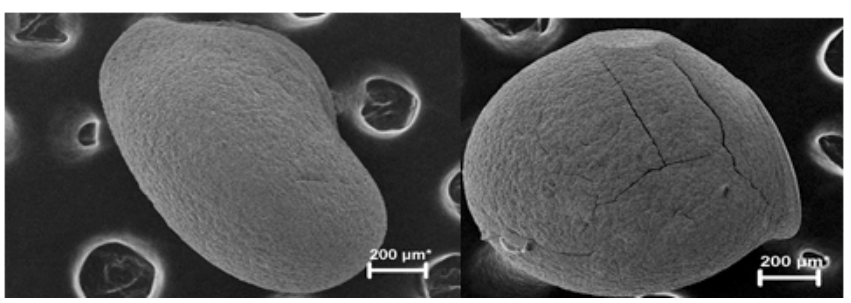

Fig.2. Colored microcapsule charged with Ruby or Violet Reactive Dye

Fig.3. Colored microcapsule charged with Ruby Metal Complex Dye

\section{Physico-chemical characterization}

FT-IR Spectroscopy

Determining of the interaction type between the reactive dye and white polymeric matrix

FT-IR analysis for ruby and violet reactive dyes adsorbed by white microcapsules, leads to the fact that the maximum absorption bands for the white polymeric matrix, are located on the next frequency values: $3231 \mathrm{~cm}^{-1}$ for - 


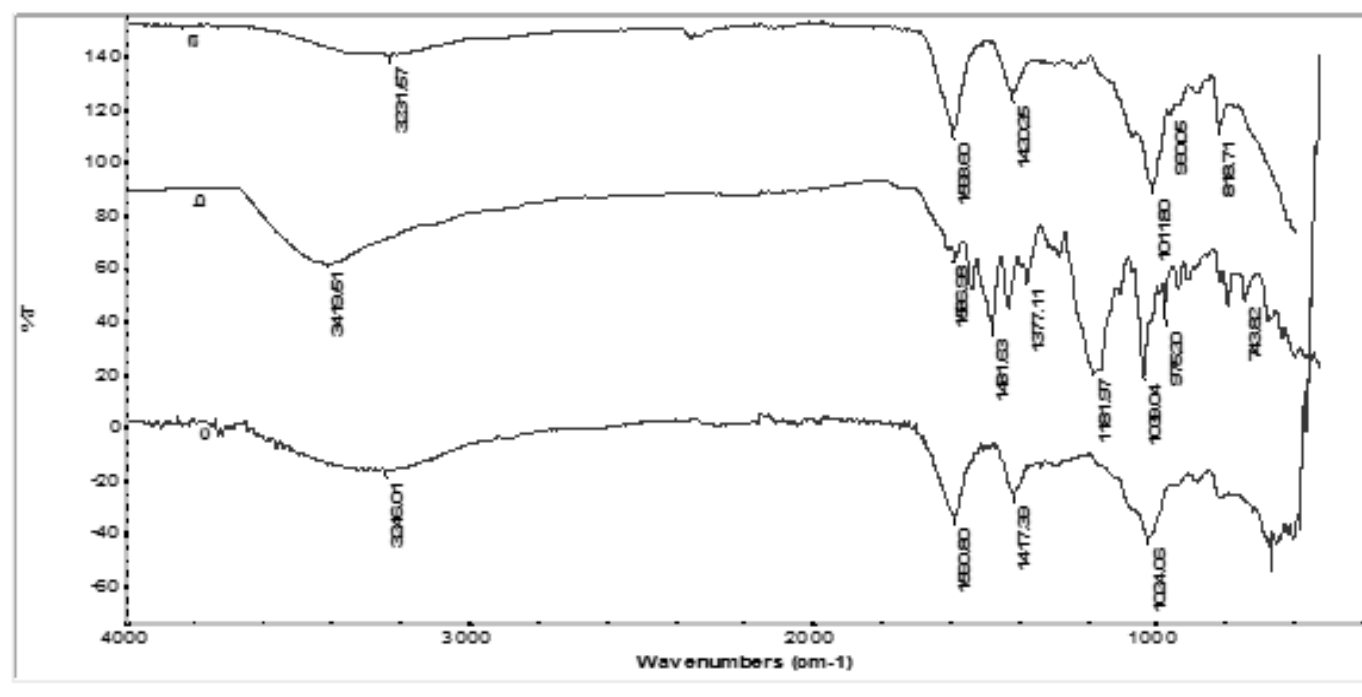

Fig. 4. a) White polymeric matrix; b) Ruby or Violet reactive dye; c) Colored microcapsules

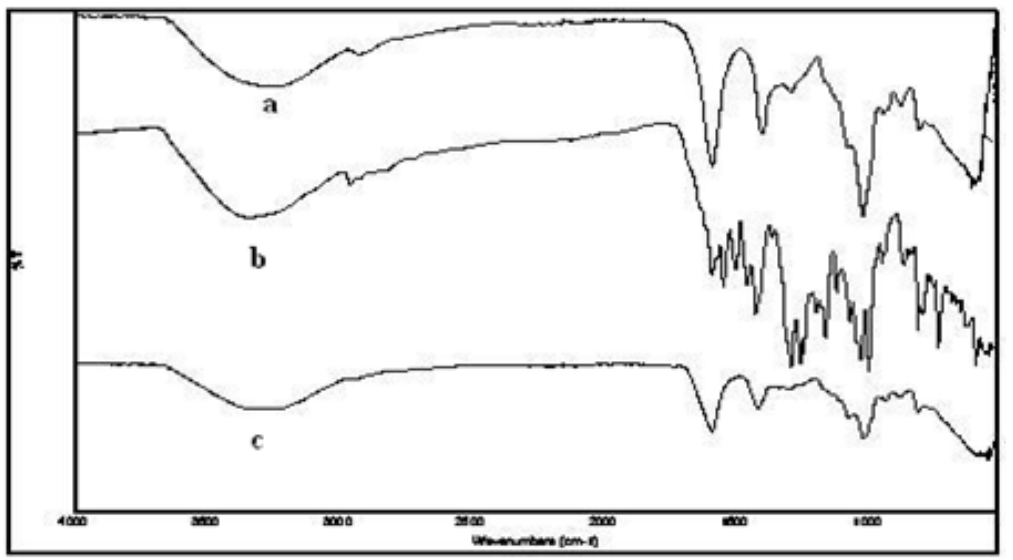

Fig. 5 - FT-IR spectra: a) White polymeric matrix; b) Ruby metal complex dye; c) Colored microcapsules

OH groups; - $1593 \mathrm{~cm}^{-1}$ and $1420 \mathrm{~cm}^{-1}$ for $\mathrm{COO}^{-1}$ groups; $1011 \mathrm{~cm}^{-1}$ for -CO- groups. It finds that the maximum absorption peak at $3231 \mathrm{~cm}^{-1}$ of $-\mathrm{OH}$ groups of white polymeric matrix, is displaced and affected at $3246 \mathrm{~cm}^{-1}$ in the case of colored microcapsules containing reactive dye, due to formation of weak intermolecular hydrogen bonds and dipole - dipole interactions type, between the -OH groups and $-\mathrm{N}=\mathrm{N}$ - groups and/or aromatic residues of the reactive dye. We see a movement and an affectation of maximum absorption peaks from $1593 \mathrm{~cm}^{-1}$ and 1420 $\mathrm{cm}^{-1}$ for $\mathrm{COO}^{-1}$ groups of white polymeric matrix to lower wavenumber $1590 \mathrm{~cm}^{-1}$ and $1417 \mathrm{~cm}^{-1}$ in the case of colored microcapsules, due to weak electrostatic interactions with $-\mathrm{N}=\mathrm{N}$ - groups (having streching vibration to $1586 \mathrm{~cm}^{-1}$ and $1481 \mathrm{~cm}^{-1}$ ) of the reactive dye. We can assume that between the polymer matrix and reactive dye (in ruby or violet shades) we are dealing only with the absorption based on physical forces, which favors a time controlled-release in water of the reactive dye, at ambient temperature.

Determining of the interaction type between the ruby metal complex dye and white polymeric matrix

FT-IR analysis of ruby metal complex dye adsorbed by white microcapsules leads to the fact that the maximum absorption bands for white polymeric matrix and ruby metal complex dye are located on the next frequency values: $3231 \mathrm{~cm}^{-1}$ for $-\mathrm{OH}$ groups; $1593 \mathrm{~cm}^{-1}$ and 1420 $\mathrm{cm}^{-1}$ for $\mathrm{COO}^{-1}$ groups; $1011 \mathrm{~cm}^{-1}$ for -CO-groups; 1430 $\mathrm{cm}^{-1}$ for $-\mathrm{NO}_{2}$ groups, in the ruby dye. It finds that the maximum absorption peak at $1593 \mathrm{~cm}^{-1}$ of the white polymeric matrix for $\mathrm{COO}^{-1}$ groups is displaced at $1590 \mathrm{~cm}$ 1 , in the case of colored polymeric microcapsules. It finds that the maximum absorption peak at $1420 \mathrm{~cm}^{-1}$ of the white polymeric matrix for $-\mathrm{COO}^{-1}$ groups is displaced at $1417 \mathrm{~cm}^{-1}$, in the case of colored polymeric microcapsules. It finds that the maximum absorption peak at $1430 \mathrm{~cm}^{-1}$ for polar -NO groups of ruby metal complex dye is displaced at $1453 \mathrm{~cm}^{-1}$, in the case of colored polymeric microcapsules. We can assume that we are dealing with electrostatic interactions between hydrofile groups of polymer matrix and polar - $\mathrm{NO}_{2}$ groups of ruby metal complex dye. So the ruby metal complex dye remains embedded in the polymeric matrix and it can not be released from the microcapsules at ambient temperature.

UV-Vis spectroscopy (colorimetric analysis)

Relative concentration determination of the reactive dye within the microcapsules

It was performed colorimetric analysis to dyestuffs solutions samples to determine the relative concentrations of reactive dyes in colored microcapsules in ruby and violet shades. For this we've determined the maximum absorbance in UV-Vis absorption spectra, for each reactive dye, to:

-standard samples of known concentration: $52 \mathrm{~g} / \mathrm{L}$ for ruby and $49 \mathrm{~g} / \mathrm{L}$ for violet dye;

- corresponding filtered samples, resulted after colored microcomposites isolation;

- samples of the primary extract, resulting after the desorption in water of the dye contained by the microcapsules.

It was concluded that the two reactive dyes respect Lambert-Beer law and from the calculations were obtained the following results: Dye concentration in the colored polymeric microcomposites: Conc $_{R}=0.29 \%$; Conc $_{V}=$ 0.15\%; Microencapsulation yield: $Y_{R}{ }_{R}=59 \% ; Y_{V}=32.3 \%$. 
Table 1

SPECTRAL PARAMETERS OF THE INVESTIGATED REACTIVE DYES

\begin{tabular}{|c|c|c|c|c|c|c|c|}
\hline $\begin{array}{c}\text { Reactive } \\
\text { Dye }\end{array}$ & $\begin{array}{c}\text { Max. abs. } \\
\lambda_{\max }(\mathbf{n m})\end{array}$ & $\begin{array}{c}\text { Standard } \\
\text { Absor- } \\
\text { bance }\end{array}$ & $\begin{array}{c}\text { Standard } \\
\text { Conc. } \\
(\mathrm{g} / \mathrm{L})\end{array}$ & $\begin{array}{c}\text { Extract } \\
\text { Absor- } \\
\text { bance }\end{array}$ & $\begin{array}{c}\text { Extract } \\
\text { Conc. } \\
(\mathrm{g} / \mathrm{L})\end{array}$ & $\begin{array}{c}\text { Filtrate } \\
\text { Absor- } \\
\text { bance }\end{array}$ & $\begin{array}{c}\text { Filtrate } \\
\text { Conc. } \\
(\mathrm{g} / \mathrm{L})\end{array}$ \\
\hline Ruby & $522 ; 544$ & 2.3187 & $1.733^{*} 10^{-2}$ & 1.3131 & $0.9814^{*} 10^{-2}$ & 0.4206 & $0.3144^{*} 10^{-2}$ \\
\hline Violet & 543 & 0.9360 & $1.633^{*} 10^{-2}$ & 0.2907 & $0.507^{*} 10^{-2}$ & 0.3193 & $0.557^{*} 10^{-2}$ \\
\hline
\end{tabular}

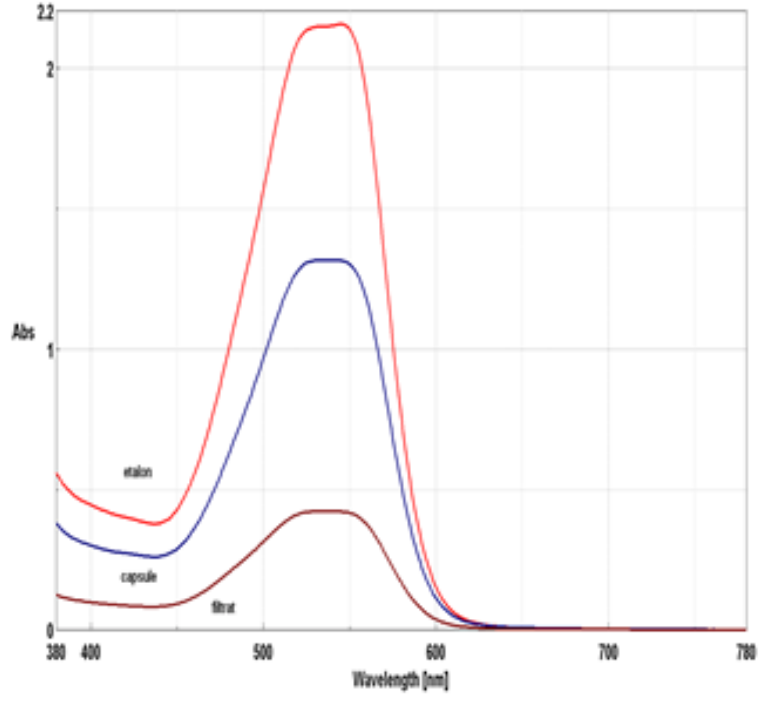

Fig.6 - UV-Vis spectrum of Ruby reactive dye samples: standard, extract, filtrate

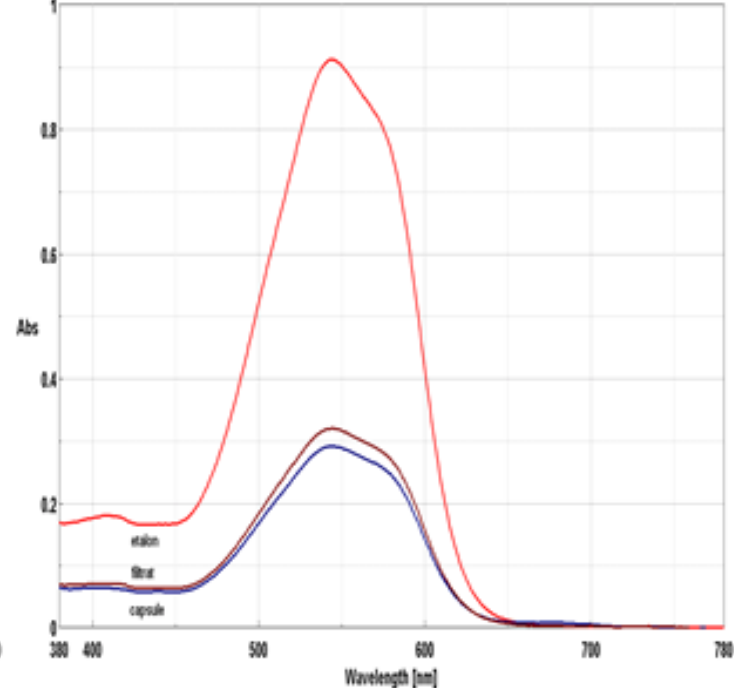

Fig.7 - UV-Vis spectrum of Violet reactive dye samples: standard, filtrate, extract

Controlled release was followed by UV-Vis measurements at $\lambda_{\text {ax }}=515 \mathrm{~nm}$. Test conditions:

1) $\mathrm{pH}=6.5$ and 2) $\mathrm{pH}=8$, with continued stirring, to approx. $70 \mathrm{rpm}$ at ambient temperature.

After 225 min of placing the colored microcapsules in water (stirring continuously), we found that absorbance of the dye is almost constant at both $\mathrm{pH}=6.5$ and $\mathrm{pH}=8$, but reaches a max. of 2-3\% (fig. 9). In a slightly alk. medium is found that the dye release is very low, in time.

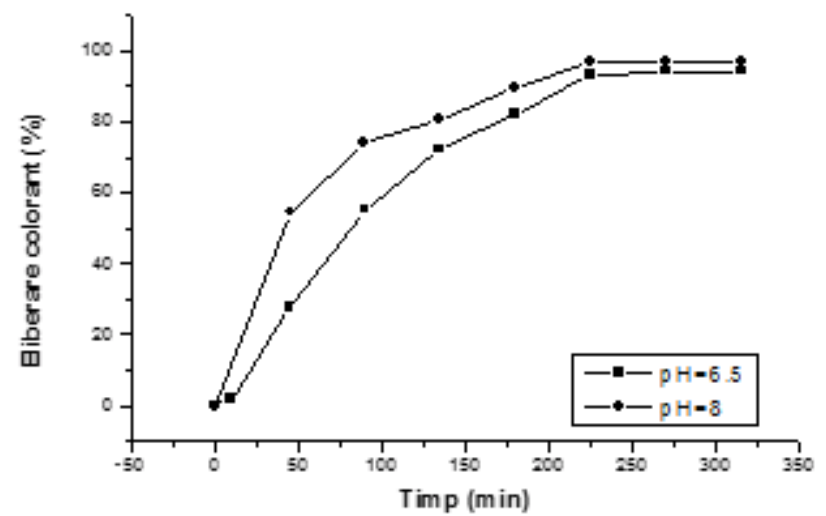

Fig. 8. Time (min) controlled-release (\%) of the Violet Reactive Dye

Coloristic characterisation of the colored polymeric microcomposites

At cotton dyeing were used both colored microcomposites (in ruby and violet shades) and standard unencapsulated reactive dyes. Before dyeing, the colored microcomposites were suspended in water, maintained $24 \mathrm{~h}$ with stirring, for reactive dye release. We worked according to the known dyeing technology, at $40-60^{\circ} \mathrm{C}$ temperature, 1:40 fleet report and finally the decolored 


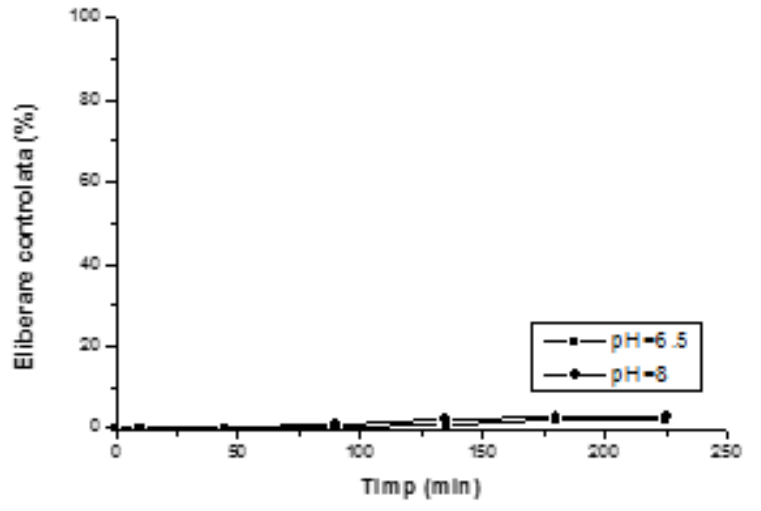

Fig. 9. Time ( $\mathrm{min}$ ) controlled-release (\%) of the Ruby Metal Complex Dye

microcomposites were isolated. Further, was used the colored filtrate to dyeing. Were made corresponding dyeings to three different dyeing concentrations: $1 \% ; 1.5 \%$, $2 \%$. Have resulted coloristic dyeing intensities close to those of standard reactive dyes. Coloristic resistences of dyed samples are similar to those given by standard dyes: 1) Xe light resistance: $4-5 ; 2$ ) Concentration of dyeing: 12\%; 3) Water resistance: 4-5 / 4-5 / 4-5; 4) Resistance to acid sweat: 4-5 / 4-5 / 4-5; 5) Wet friction resistance: $5 ; 6$ ) Dry friction resistence: 5 .

\section{Conclusions}

We have obtained two new colored materials in ruby and violet shades in form of polymeric microcomposites used to dye cellulose fibers (cotton.);

We have obtained one new colored material in ruby shade in form of polymeric microcomposites, which cannot be used to dye protein support (wool, leather);

We developed a modernized and ecological laboratory technology of conditioning of investigated coloring materials by microencapsulation in a biodegradable natural polymer;

From FT-IR spectra we can assume that we are dealing only with absorption based on physical forces between polymeric matrix and reactive dyes, which favors a time controlled-release of the dye contained by the microcapsules;
From FT-IR spectra we can assume that we are dealing with electrostatic interaction between hydrofile groups of polymeric matrix and polar $-\mathrm{NO}_{2}$ groups of ruby metal complex dye, which prevents the time controllled-release of the metal complex dye, contained by the microcapsules.

From the isolation data of colored polymeric microcomposites and colorimetric analysis in the UV-Vis field it was determined the optimal dye concentration in microcapsules, Conc $=0.29 \%$ and Conc $_{\mathrm{V}}=0.15 \%$, to ensure the optimal dyeing concentration to the cellulosic textile support (cotton) at 1, 1.5, 2\% values. It was demonstrated the functionality and utility of microencapsulation technology, with microencapsulation efficiency between $30-60 \%$.

Aknowledgements: The work was funded by Executive Agency for Higher Education, Research, Development and Innovation (UEFISCDI) under The Ministry of Education from Romania. We thank Mr. dr. Valentin Raditoiu to colorimetric analysis and absorption spectra in UV-Vis and Mr. Marian Deaconu to residual water discoloration method made.

\section{References}

1.FERRES J. M. R., SERRABASA E. P., LIRO M., (1998), ES 2,112,150 (B01, J 13/10);

2. CHOKYUN R., SANCHEZ D. R., (1988), US 4,744,933 (A61, K9/16);

3. SHEVCHENKO A.V., BIRJUKOVA L.A.; (1999), RU 2,132,224 (C08, J 9/ 32);

4. MING XU, (2007), WO (C09, B67/00B4F);

5.TAKASHI O., HIRONORI S., KAZUO S., (1998) JP 63252543 (A) (A61, $\mathrm{K} 8 / 11 \mathrm{C})$;

6.YOUNG SIL JEON, JING LEI, JI-HEUNG KIM, Dye adsorption characteristics of alginate/ polyaspartate hydrogels, Journal of Industrial and Engineering Chemistry, 14, 2008, 726-731.

7. WAN NGAH W. S., TEONG L. C., HANAFIAH M. A. K. M., Adsorption of dyes and heavy metal ions by chitosan composites, A review, Carbohydrate Polymers , 83, 2011, 1446-1456;

8.PERETZS., CINTEZA O., Removal of some Nitrophenol Contaminants Using Alginate Gel Beads, Colloid and Surfaces A. Physicochemical and Engineering Aspects, 319, 2008, 165-172

Manuscript received: 7.11 .2016 